\title{
Knowledge of and adherence to standard precautions in a hemodialysis unit: a cross-sectional study
}

\author{
Laura Prado Medeiros', Kamila Silva de Miranda", Thayna Martins Gonçalves"', Deusdélia Dias Magalhães Rodrigues'v, \\ Karen Renata Nakamura Hiraki ${ }^{\mathrm{V}}$, Marilia Duarte Valim ${ }^{\mathrm{VI}}$, Monica Taminato ${ }^{\mathrm{VII}}$, Richarlisson Borges de Morais ${ }^{\mathrm{VIII}}$ \\ Universidade Federal de Uberlândia (UFU), Uberlândia (MG), Brazil
}

\begin{abstract}
'Nurse Resident, Multiprofessional Residency Program, Universidade Federal de Uberlândia, Uberlândia (MG), Brazil.

(D) https://orcid.org/0000-0001-6467-2883

"Nursing Student, Universidade Federal de Uberlândia, Uberlândia (MG), Brazil.

(D) https://orcid.org/0000-0001-6975-3746

"'Nursing Student, Universidade Federal de Uberlândia, Uberlândia (MG), Brazil.

(D) https://orcid.org/0000-0001-8256-8596

"MSc. Nurse, Hospital de Clínicas, Universidade Federal de Uberlândia, Uberlândia (MG), Brazil. (D) https://orcid.org/0000-0003-2177-7575
\end{abstract}

vphD. Associate Professor, Instituto de Ciências Biomédicas, Universidade Federal de Uberlândia, Uberlândia (MG), Brazil.

(D) https://orcid.org/0000-0002-9382-4548

viphD. Adjunct Professor, Faculdade de Enfermagem, Universidade Federal de Mato Grosso, Cuiabá (MT), Brazil.

(D) https://orcid.org/0000-0002-2746-1865

vilPhD. Adjunct Professor, Escola Paulista de Enfermagem, Universidade Federal de São Paulo, São Paulo (SP), Brazil.

(D) https://orcid.org/0000-0003-4075-2496

VIIMSc. Doctoral Student and Assistant Professor, Escola Técnica de Saúde, Universidade Federal de Uberlândia, Uberlândia (MG), Brazil.

(D) https://orcid.org/0000-0003-0009-1750

KEY WORDS (MeSH terms):

Universal precautions.

Accidents, occupational.

Patient safety.

Nursing, team

Renal dialysis.

\section{AUTHORS' KEY WORDS:}

Standard precautions.

Nursing staff.

Worker's health.

Occupational health.

Patient safety.

Hemodialysis.

\begin{abstract}
BACKGROUND: Standard precautions (SPS) are recommended safety measures for healthcare professionals to follow, with a view to preventing healthcare-related infections (HCRIs) and for their own protection. Inadequate adherence to these measures can lead to occurrences of occupational accidents and HCRIs. OBJECTIVES: To ascertain the knowledge of and adherence to SP measures among the nursing staff of a hemodialysis service and the relationship of these variables to occurrences of work accidents with biological material.

DESIGN AND SETTING: Descriptive cross-sectional and correlational study with a quantitative approach developed in a hemodialysis clinic in Minas Gerais.

METHODS: Data were collected through sociodemographic questionnaires and questionnaires on knowledge of and adherence to SPS.

RESULTS: 29 professionals participated in the study. It is noteworthy that all of them had already participated in training related to SPs. However, no relationship was identified between knowledge of (15.17 points) and adherence to (71.86 points) SPs. In addition, inferential analysis showed that there was a relationship between suffering a work accident with biological material and the sociodemographic data and knowledge of and adherence to standard precautions.

CONCLUSION: Knowledge of the SPs that had been established did not mean mastery of the subject. Despite positive results regarding adherence, factors requiring improvement were observed. It was possible to infer the characteristics that gave rise to greater risk of occurrences of accidents at work. Thus, this study showed the importance of assessing knowledge of and adherence to SP, in order to optimize and direct continuing education towards resolving occupational exposure.
\end{abstract}

\section{INTRODUCTION}

According to the Centers for Disease Control and Prevention (CDC), standard precautions (SPs) are essential safety measures for healthcare with a view to protecting the client against healthcare-related infections (HCRIs), and for professional protection against occupational exposure to potentially contaminated biological material (PCBM). ${ }^{1}$

This set of SP measures is composed of the following: hand hygiene before and after contact with patients or areas adjacent to them; use of personal protective equipment (PPE), including glasses, mask, apron and procedure gloves; correct handling and disposal of sharps; and vaccination against hepatitis $B .^{2,3}$

It is known that low adherence to SPs contributes to growing numbers of occupational accidents in healthcare services. ${ }^{3}$ Professionals who do not make adequate use of PPE and who handle sharps are exposed to occupational risks. In this context, the nursing professionals of hemodialysis services can be highlighted, given that they handle sharp devices and potentially contaminated equipment on a daily basis. ${ }^{4,5}$

It is important to consider that chronic renal patients who are undergoing renal replacement therapy (RRT) are in a vulnerable condition. They are subjected to invasive procedures every week, which are performed in a hospital environment, where pathogens and multidrug-resistant agents are present. ${ }^{6}$ Studies have demonstrated occurrences of infection among patients on $\mathrm{RRT}^{7,8}$ thus highlighting the prevalence of infections caused by resistant microorganisms among patients on dialysis and awaiting kidney transplantation. ${ }^{9}$ 
In view of the complexity of the hemodialysis service and the vulnerability of patients subject to RRT, the nursing team at these services takes on an important role of responsibility for care, in order to ensure patient safety and their own safety through adherence to SP.

However, studies have revealed low adherence to SP among nursing professionals ${ }^{10,11}$ and have identified factors that determine inadequate adherence. Recklessness, shortage of materials in hospital units, ${ }^{12}$ insufficient knowledge and work overload have been highlighted. ${ }^{13}$

In view of the above, we perceived that there was a gap in the literature. In particular, there seemed to be a need to assess the knowledge of and adherence to SP among the nursing team working on hemodialysis, considering that these variables are directly related to occurrences of HCRIs, occupational accidents with exposure to PCBM and the quality and safety of healthcare.

\section{OBJECTIVE}

The aim of this study was to ascertain the knowledge and adherence of the nursing staff of a hemodialysis unit with regard to SP measures and correlate these variables with occurrences of occupational accidents with PCBM.

\section{METHODS}

This study followed the recommendations of the Strengthening the Reporting of Observational Studies in Epidemiology (STROBE) initiative. ${ }^{14}$ It was a descriptive quantitative cross-sectional and correlational study performed at a hemodialysis clinic in the city of Uberlândia, Minas Gerais, Brazil. This is a private clinic accredited to the Brazilian National Health System (Sistema Unico de Saúde, SUS) that performs an average of 3,500 hemodialysis sessions per month.

A non-probabilistic or convenience sample was used. All the nursing professionals at the institution who had worked there for more than six months with a minimum workload of 20 hours a week were eligible for inclusion in the study, provided that they were not on vacation, maternity leave or sick leave at the time of data collection.

Professionals whose work exclusively involved administrative activities were excluded. In addition, those who were participating in training related to safety measures at the time of data collection were also excluded, as this training would possibly overvalue their knowledge about SP.

\section{Data collection and statistical analysis}

Data were collected using self-administered questionnaires: one seeking sociodemographic data and variables relating to occurrences of occupational accidents with PCBM; a questionnaire to assess knowledge of SP (Standard Precautions
Knowledge Questionnaire, SPKQ);15 and another questionnaire to measure adherence to SPs (Standard Precautions Adherence Questionnaire, SPAQ). ${ }^{16}$

The SPKQ had previously been validated for Brazilian realities. It contains 20 questions relating to healthcare professionals' knowledge of SP, and has proved to be stable due to its reliability according to the intraclass correlation coefficient, which was calculated as 0.91 , and its satisfactory agreement with the mean kappa index. ${ }^{15}$

The SPAQ is another instrument that has been translated and validated for use in Brazil. ${ }^{16}$ It is composed of 20 questions relating to adherence to SP, in a Likert-type format, ranging from 1 to 4 points for each question.

For data compilation, double entry was used independently, in order to eliminate possible mistakes. The data were analyzed by means of the R software, version 3.6.3, and the R Studio software, version 1.2.5001 (Integrated Development for R; RStudio, PBC, Boston, MA, United States).

Descriptive statistical techniques were used for presentation of the numerical data. Categorical data were expressed in terms of frequencies (absolute and relative). To identify the relationship between occurrences of accidents with PCBM and the other variables studied, bivariate analysis was performed using Fisher's exact test. Simple and multiple linear regression models were used to identify the relationship of the scores obtained in the SPAQ and the SPKQ with occurrences of accidents with PCBM. The significance level was taken to be alpha $<0.05$.

\section{Ethical issues}

This study was approved by our institution's ethics committee for research on human beings, under CAAE number 09987318.7.0000.5152, dated July 17, 2019. Confidentiality and anonymity for the participants was ensured, in accordance with resolution no. 466/2012 of the National Health Council.

\section{RESULTS}

Twenty-nine nursing professionals participated in the study who were active in the outpatient dialysis service of our institution participated in this study. These comprised 24 nursing technicians $(82.75 \%)$ and five nurses $(17.24 \%) ; 79.31 \%$ were female; the participants' mean age was 39.1 years; their mean length of professional experience was 13.0 years; and their mean length of experience of dialysis was 11.9 years (Table $\mathbf{1}$ ).

Regarding participation in training relating to SPs, 29 (100\%) responded that they had had some training: 26 (89.65\%) underwent this in 2019 and the majority (55.17\%) received their training from the institution's Internal Accident Prevention Commission (IAPC). It was noteworthy that 26 (89.65\%) of the nursing staff surveyed expressed a desire to receive training and updates on SP measures. 
Table 1. Distribution of the nursing staff according to gender, age, education level, accidents with sharps, accidents with potentially contaminated biological material, participation in training, vaccination status against hepatitis $B$ and knowledge of vaccine response, at a hemodialysis clinic in the city of Uberlândia, Minas Gerais, Brazil, 2020 ( $\mathrm{n}=29)$

\begin{tabular}{lcc} 
Variables & $\mathbf{n}$ & $\%$ \\
$\begin{array}{l}\text { Participants' gender } \\
\text { Male }\end{array}$ & 6 & 20.69 \\
$\quad$ Female & 23 & 79.31 \\
\hline Age (years) & & \\
$\quad 20$ to 30 & 5 & 17.24 \\
30 to 40 & 10 & 34.48 \\
40 to 50 & 10 & 34.48 \\
50 to 60 & 2 & 6.89 \\
$>60$ & 1 & 3.44 \\
Education level reached & & \\
Completed high school & 19 & 65.51 \\
Undergraduate at university/college & 4 & 13.79 \\
Graduated from university/college & 1 & 3.44 \\
Specialization & 5 & 17.24 \\
Work accidents with PCBM & & \\
No & 16 & 55.17 \\
Yes & 13 & 44.82
\end{tabular}

Accidents with PCBM consisting of unhealthy skin or mucus, involving contact with potentially contaminated blood or body fluids

$\begin{array}{lll}\text { No } & 19 & 65.51 \\ \text { Yes } & 10 & 34.48\end{array}$

How many times have you had an accident with PCBM consisting of unhealthy skin or mucus, involving contact with potentially contaminated body fluids?

$\begin{array}{lcc}\text { None } & 18 & 62.06 \\ \text { Once } & 3 & 10.34 \\ \text { Twice } & 2 & 6.89 \\ \text { Four times } & 2 & 6.89 \\ \text { Several (more than four) } & 3 & 10.34 \\ \text { Missing response } & 1 & 3.44\end{array}$

Accidents at work with biological material by means of sharps or exposure to mucous membranes or unhealthy skin in the last 12 months (last year)

$\begin{array}{lcc}\text { No } & 24 & 82.75 \\ \text { Yes } & 5 & 17.24\end{array}$

Participation in training on standard precautions offered by the employing institution

Yes $\quad 29 \quad 100.00$

Schedule for complete hepatitis B vaccination (3 doses) $\begin{array}{lll}\text { Yes } & 29 & 100.00\end{array}$

Underwent a medical examination to detect antibodies for hepatitis B

$\begin{array}{lll}\text { No } & 1 & 3.44\end{array}$

$\begin{array}{lll}\text { Yes } & 28 & 96.55\end{array}$

Examination result regarding antibodies for hepatitis B $\begin{array}{lll}\text { Positive } & 14 & 48.27\end{array}$ $\begin{array}{lll}\text { Negative } & 8 & 27.58\end{array}$ I don't know $\quad 3 \quad 10.34$ Missing response $\quad 4 \quad 13.79$

$\mathrm{n}=$ absolute number; $\%$ = percentage; $\mathrm{PCBM}=$ potentially contaminated biological material.
When asked about changing devices for disposing of sharps when they reached two-thirds of their capacity, 21 (72.41\%) reported that the device was changed when it reached its maximum recommended capacity, while eight (27.58\%) reported that they did not do this replacement.

In analyzing the responses to the SPKQ, the average knowledge of SPs was 15.17 points; the maximum score was 18 and the minimum was 5 points. With regard to adherence to SPs (SPAQ), the mean score was 71.86 points, the maximum was 80 and the minimum was 45 points. The relationship between knowledge of and adherence to PP was calculated by means of Kendall's correlation between the scores. A weak correlation of $0.221(\mathrm{P}=0.126)$ was noted, which showed that there was no relationship between knowledge of and adherence to SPs in the sample studied.

The majority of the participants correctly judged each item in the SPKQ questionnaire. It was noteworthy that $79.31 \%$ said that they knew what SPs were. However, $82.75 \%$ considered question 3 (Q3) to be true, which states that SPs have the main objective of protecting the healthcare team, thereby devaluing patient safety. In addition, more than $41 \%$ of the professionals surveyed judged Q18 to be incorrect or did not know how to judge Q18: "When providing nursing care to patients with hepatitis $\mathrm{C}$ or human immunodeficiency virus (HIV), it is necessary to adopt only the SP measures" (Table 2).

Regarding adherence to SP, it was highlighted that $6.89 \%$ of the nursing professionals performed hand hygiene before providing assistance to patients only rarely or sometimes. In procedures with the possibility of contact with urine or feces, $100 \%$ of the participants reported always wearing gloves. However, in procedures with the possibility of contact with unhealthy skin, adherence to use of this equipment decreased (82.75\%). Regarding the use of goggles and a mask, $79.31 \%$ stated that they always used this equipment. However, only $48.27 \%$ use the respiratory etiquette when coughing or sneezing (Table 3).

In correlating occurrences of biological accidents with PCBM and other variables, significance at the $5 \%$ level was identified through Fisher's exact test. There were associations with the following response variables: suffering an occupational accident with PCBM $(\mathrm{P}<0.001)$; suffering a work accident with PCBM through needlestick or exposure to mucous membranes or unhealthy skin over the last 12 months $(\mathrm{P}=0.036)$; the frequency with which occupational accidents with $\mathrm{PCBM}$ were notified $(\mathrm{P}<0.001)$; results from examinations for antibodies to hepatitis $\mathrm{B}$ post-vaccination ( $\mathrm{P}=0.021)$; responses to question $1(\mathrm{Q} 1)$ of the SPKQ, "Do you know what the standard precautions (SP) measures are?" $(\mathrm{P}=0.002)$; responses to $\mathrm{Q} 6$ of the SPKQ, "Since the use of gloves can prevent hand contamination, it is not necessary to clean your hands after removing the gloves" $(\mathrm{P}<0.001)$; responses to $\mathrm{Q} 18$ of the SPKQ, "When providing nursing care to patients with hepatitis 
Table 2. Descriptive analysis on knowledge of standard precautions in a nursing team at a hemodialysis clinic in the city of Uberlândia, Minas Gerais, Brazil, 2020 ( $\mathrm{N}=29)$

\begin{tabular}{|c|c|c|c|}
\hline Knowledge of standard precautions & True/yes & False/no & I don't know \\
\hline Q1 - Do you know what standard precaution measures are? & $23(79.31)$ & $0(0.0)$ & $5(17.24)$ \\
\hline $\begin{array}{l}\text { Q2 - Standard precautions should only be applied to patients diagnosed with } \\
\text { infection or patients who are in the incubation period for a given infection. }\end{array}$ & $4(13.79)$ & $20(68.96)$ & $3(10.34)$ \\
\hline $\begin{array}{l}\text { Q3 - The main objective of adhering to standard precaution measures is to protect } \\
\text { the healthcare team. }\end{array}$ & $24(82.75)$ & $2(6.89)$ & $3(10.34)$ \\
\hline Q5 - Hand hygiene should be performed when providing care to different patients. & $26(89.65)$ & $2(6.89)$ & $0(0)$ \\
\hline $\begin{array}{l}\text { Q16 - Symptomatic respiratory patients (coughing, sneezing, etc.) must be kept at } \\
\text { least one meter away from other patients in the ward. }\end{array}$ & $22(75.86)$ & $2(6.89)$ & $4(13.79)$ \\
\hline
\end{tabular}

Table 3. Descriptive analysis on adherence to standard precautions in a nursing team at a hemodialysis clinic in the city of Uberlândia, Minas Gerais, Brazil, 2020 ( $n=29)$

\begin{tabular}{|c|c|c|c|c|c|}
\hline Adherence to standard precautions & $\mathbf{N}$ & $\mathbf{R}$ & S & 0 & A \\
\hline Q1 - I perform hand hygiene before assisting the patient. & $0(0)$ & $1(3.44)$ & $1(3.44)$ & $7(24.13)$ & $20(68.96)$ \\
\hline $\begin{array}{l}\text { Q14 - I use a protective mask when there is the possibility of contact with } \\
\text { splashes of blood, body fluids, secretions or excretions. }\end{array}$ & $0(0)$ & $0(0)$ & $1(3.44)$ & $3(10.34)$ & $23(79.31)$ \\
\hline Q18 - I do not recap used needles. & $5(17.24)$ & $4(13.79)$ & $3(10.34)$ & $5(17.24)$ & $10(34.48)$ \\
\hline
\end{tabular}

$\mathrm{N}=$ never; $\mathrm{R}=$ rarely; $\mathrm{S}=$ sometimes; $\mathrm{O}=$ often; $\mathrm{A}=$ always.

C or HIV, it is necessary to adopt only the standard precaution measures" ( $\mathrm{P}=0.004)$; responses to Q20 of the SPAQ, "When I cough or sneeze, I use a disposable handkerchief to cover my mouth and nose, then I dispose of it and clean my hands" ( $\mathrm{P}=0.049)$.

Univariate analysis was carried out on responses to the indicator of suffering an accident with PCBM. All the variables of the SPKQ and SPAQ were used as covariates. Variables with significance at $10 \%$ in univariate analysis were then subjected to multivariate analysis.

In making multivariate adjustments using the significant variables, the variables in the final multivariate model that explained suffering an accident with PCBM with a significance level of 5\% were the following: occurrence of a work accident with potentially contaminated sharps (standard deviation, SD: \pm 1.409 ; confidence interval, CI: [0.935; 6,867]; $\mathrm{P}=0.019$ ); and identifying question 18 of the SPKQ as false, i.e. "When providing nursing care to patients with hepatitis C or HIV, it is necessary to adopt only standard precaution measures" (SD: \pm 1.297 ; CI: [0.566; 6.054]; $\mathrm{P}=0.028$ ).

Thus, the odds ratio (OR) between occurrence of work accidents with potentially contaminated sharps and the variable "If you suffered a work accident with potentially contaminated sharps", showed that nursing professionals who reported having already suffered this type of accident were 27 times more likely to have accidents in this way than were those who had not suffered a work accident with sharps (OR: 27.51; CI: [2.546; 959.731]; $\mathrm{P}=0.019$ ). In addition, those who believed that the sentence in question SPKQ-18 was false ("When providing nursing care to patients with hepatitis C or HIV, it is necessary to adopt only standard precaution measures") were 17 times more likely to suffer an accident through working with PCBM than were those who believed that the sentence was true or did not know whether they believed the sentence (OR: 17.27; CI: [1.761; 425.760]; P = 0.028).

\section{DISCUSSION}

After recruiting nursing professionals and applying the questionnaires, the sociodemographic description and the relationship between occurrences of occupational accidents and other variables studied were assessed.

There was a predominance of professionals at technical level, which can be explained by the provisions of Ordinance No. 389/14, which determines that in hemodialysis services, one nursing technician is required for every four patients and one nurse per shift is required for every 35 patients. ${ }^{17}$ Thus, it is inferred that the demand for professionals at technical level will always be greater than the demand for nurses. 
In a previous study, it was observed that $61.7 \%$ of the population of nursing professionals was up to 40 years old. ${ }^{18}$ This corroborates our results, in which the average age was found to be 39.1 years. The prevalence of young adult professionals explains the average of 13 years of professional experience.

Another result presented by $100 \%$ (29) of the professionals was that they had all participated in training provided by the employing institution within the last 12 months, with a SP approach. Their responses to Q1 of the SPKQ ("Do you know what standard precautions measures are?") may have been determined by this fact, given the impact of continuing education in healthcare services, with a view to expanding knowledge and preparing the team for work activities, ${ }^{2,12,19}$ especially those with active methodology and protagonism of the subject. ${ }^{15}$ However, even so, it was observed that $17.24 \%$ of the professionals stated that they did not have any knowledge about SPs.

Although $79.31 \%$ of the sample claimed to know about SPs, the antagonistic result stood out, in which $82.75 \%$ responded that Q3 of the SPKQ was true ("Adherence to standard precaution measures has the main objective of protecting the healthcare team"), which incorrectly presents the main objective of SPs. A similar result was observed in a study in which $67.5 \%$ of the nurses believed that the main objective of SPs was to protect the healthcare team, while ignoring the protection provided for patients that was involved in adherence to SPs. ${ }^{12}$

On the other hand, a study carried out in São Paulo showed results that were contrary to those of previous studies, in which $87.6 \%$ of the participating nurses disagreed with the statement contained in Q3 of the SPKQ. ${ }^{15}$ This result was also described in another recent study, in which $72 \%$ of the participants strongly disagreed with the objective of the SPs that is presented in that question. ${ }^{20}$

The participants in our study showed positive results regarding the SPAQ questions that investigate the frequency of hand hygiene at different times or situations, namely: Q1 - before providing assistance to the patient; Q2 - before performing aseptic techniques; and Q3 - after exposure to potentially contaminated body fluids. This result demonstrates the coherence and ability of the professionals to recognize the moments when hand hygiene is essential. However, even though these results were satisfactory, it is important to highlight that for Q1 of the SPAQ, 6.89\% of the participants presented an incoherent response to the recommendations. On the other hand, this was not repeated in Q3 of the same instrument. This suggests that nursing professionals are concerned with sanitizing their hands in order to minimize the risk of contamination when exposing themselves to potentially contaminated fluids, but give less value to the importance of this act before providing nursing care, which thus represents an important risk to patients' safety. ${ }^{21}$
From a study developed in a hemodialysis unit, it was pointed out that nursing professionals had low adherence to hand hygiene, and that they performed this technique only in $16.6 \%$ out of 1090 opportunities. ${ }^{22}$ Although hand hygiene is frequently discussed, educational interventions remain one of the important alternatives for raising professionals' awareness of this. ${ }^{23,24}$

There was significant divergence in the responses to the assertion in Q18 of the SPKQ ("When providing nursing care to patients with hepatitis C or HIV, it is necessary to adopt only the standard precaution measures"). Among the professionals surveyed, 38\% judged that this assertion was incorrect and 3\% did not know how to judge it. This was in contrast to their self-reported knowledge of SP and drew attention to the fact that the hemodialysis unit studied serves patients who are seropositive for HIV and hepatitis B and C. This result was similarly observed in two other studies: in one, only $85 \%$ judged the same statement to be correct; ${ }^{12}$ while in another study, $76.8 \%$ marked this statement as true..$^{15}$ In addition, this finding highlights the existence of stigma in caring for patients who are known to be positive for these viruses. This attitude puts nursing professionals in a situation of greater occupational risk, due to their unnecessary (excessive) and inappropriate use of PPE.

The relationship between occurrences of accidents with PCBM and the SPKQ variables shows the impact of knowledge of SPs on the prevalence of occupational accidents, since accidents with PCBM are usually associated with nonuse or inappropriate use of PPE and non-adherence to SPs. ${ }^{25,26}$ This can be shown by the result in which $80 \%$ of the professionals who suffered accidents with PCBM did not believing that just adopting SPs was enough for care directed to patients with hepatitis C or HIV.

The risk of accidents with potentially contaminated sharps was 27.51 times greater among professionals who had already had an accident. This corroborated a result observed in another study, in which $46.6 \%$ of the sample reported having already been exposed to PCBM and $63.5 \%$ of these individuals claimed to have been injured more than once. ${ }^{26}$

The importance of training in terms of biosafety practices can be emphasized: not only at work, but also in professional training, as a strategy for minimizing the impacts of lack of knowledge, ${ }^{27}$ since occupational accidents with PCBM may be associated with lack of knowledge or low participation in training activities. ${ }^{26}$ In addition, our findings contribute to directing institutional managers' attention towards professionals who are at greater risk of suffering new accidents at work with PCBM. Our findings emphasize training measures for promoting a better institutional safety climate and, thus, for also promoting health safety (for both patients and professionals) in the institution.

Although the average scores obtained from the questionnaires $(\mathrm{SPAQ}=15.17$ and $\mathrm{SPKQ}=89.82)$ were positive, the deficits in 
knowledge of and adherence to SPs become significant in view of the vulnerability of users of the renal replacement therapy service and the possible consequences for workers, such as occupational accidents and their associated morbidity, in addition to possible losses for the institution. ${ }^{3}$

In another study, it was concluded that knowledge of SPs did not necessarily mean adherence to these measures. ${ }^{12}$ This corroborates what was observed in our sample, since only a weak correlation was identified between these two variables.

It is worth mentioning that the present study was carried out in a single center, which limited the population for composition of the sample. It can therefore be suggested that further studies should be conducted, with participation of several dialysis services, in order to confirm and generalize the findings from the present study, for nursing professionals working in these services.

\section{CONCLUSION}

Although the institution evaluated in this study had provided training on SPs within the last 12 months, the professionals surveyed showed significant inconsistencies in their knowledge of SPs. We can highlight their inappropriate perception of insecurity regarding use of SPs to care for people with viral conditions such as HIV and hepatitis C.

Regarding adherence to SP, although the overall result was positive, there were reports of non-adherence to hand hygiene before performing nursing care, insufficient adherence to respiratory etiquette and inadequate needle recapping. This occurrences demonstrate that there is a need for improvements in adherence to these measures among the nursing professionals surveyed.

Furthermore, this study highlights the importance of training healthcare teams to provide them with better knowledge of and adherence to SP. It provides a stimulus for undertaking other studies in order to expand the understanding of this problem among healthcare professionals who are exposed to potentially contaminated biological material in their work practice, especially with regard to professionals working in dialysis services, given their daily exposure.

Lastly, the relationship between occurrences of accidents with potentially contaminated sharps and lack of knowledge of SPs corroborates data from the literature. This highlights the importance of evidence-based practice in order to optimize health safety, both for professionals and for patients.

\section{REFERENCES}

1. Prevention CfDCa. Guide to infection prevent for outpatient settings: minimum expectations for safe care. Atlanta: CDC; 2015. Available from: https://www.cdc.gov/infectioncontrol/pdf/outpatient/guide. pdf. Accessed in 2021 (Aug 10).
2. Piai-Morais TH, Orlandi F de S, Figueiredo RM. Fatores que influenciam a adesão às precauções-padrão entreprofissionais de enfermagem em hospital psiquiátrico [Factors influencing adherence to standard precautions among nursing professionals in psychiatric hospitals]. Rev Esc Enferm USP. 2015;49(3):478-85. PMID: 26107709; https://doi. org/10.1590/S0080-623420150000300016.

3. Porto JS, Marziale MH. Reasons and consequences of low adherence to standard precautions by the nursing team. Rev Gaucha Enferm. 2016;37(2):e57395. PMID: 27253597; https://doi.org/10.1590/19831447.2016.02.57395. Erratum in: Rev Gaucha Enferm. 2016;37(2):e57395x.

4. Souza Terra F, Costa AMDD, Figueiredo ET, et al. As principais complicações apresentadas pelos pacientes renais crônicos durante as sessões de hemodiálise. Rev Bras Clin Med. 2010;8(3):187-92.

5. Silva KA, Nunes ZB. As intervenções de enfermagem mais prevalentes em um serviço de hemodiálise frente às intercorrências com a fístula arteriovenosa durante a sessão de hemodiálise. J Health Sci Inst. 2011;29(2):110-3. Available from: https://pesquisa.bvsalud.org/portal/ resource/pt/lil-606306. Accessed in 2021 (Aug 10).

6. Sousa MRG, Camargo Silva AEB, Bezerra ALQ, et al. Prevalência de eventos adversos em uma unidade de hemodiálise [Prevalence of adverse events in a hemodialysis unit] [Prevalencia de eventos adversos en una unidad de hemodiálisis]. Rev Enferm UERJ, Rio de Janeiro. 2016;24(6):e18237. https://doi.org/10.12957/reuerj.2016.18237.

7. Barbosa D, Lima L, Silbert S, et al. Evaluation of the prevalence and risk factors for colonization by vancomycin-resistant Enterococcus among patients on dialysis. Am J Kidney Dis. 2004;44(2):337-43. PMID: 15264193; https://doi.org/10.1053/j.ajkd.2004.04.038.

8. Freitas MC, Pacheco-Silva A, Barbosa D, et al. Prevalence of vancomycinresistant Enterococcus fecal colonization among kidney transplant patients. BMC Infect Dis. 2006;6:133. PMID: 16923193; https://doi. org/10.1186/1471-2334-6-133.

9. Tokars Jl, Frank M, Alter MJ, Arduino MJ, editors. National surveillance of dialysis-associated diseases in the United States, 2000. Seminars in dialysis. 2002;15(3):162-71. https://doi.org/10.1046/j.1525-139X.2002.00051.x.

10. de Figueiredo RM, Maroldi MA. Internação domiciliar: risco de exposição biológica para a equipe de saúde [Home care: health professionals at risk for biological exposure]. Rev Esc Enferm USP. 2012;46(1):145-50. PMID: 22441278; https://doi.org/10.1590/S0080-62342012000100020.

11. Tipple AF, Silva EA, Teles SA, et al. Acidente com material biológico no atendimento pré-hospitalar móvel: realidade para trabalhadores da saúde e não saúde [Accident with biological material at the prehospital mobile care: reality for health and non-healthcare workers]. Rev Bras Enferm. 2013;66(3):378-84. PMID: 23887787; https://doi.org/10.1590/ s0034-71672013000300012.

12. Faria LBG, Santos CTB, Faustino AM, Oliveira LMAC, Cruz KCT. Conhecimento e adesão do enfermeiro às precauções padrão em unidades críticas [Knowledge and adherence of the nurse to standard precautions in critical units]. Texto Contexto Enferm. 2019;28:e20180144. http://dx.doi.org/10.1590/1980-265X-TCE-2018-0144. 
13. Valim MD, de Morais RB, Marziale MHP. Instrumentos e fatores impactantes sobre o conhecimento das medidas de precauçõespadrão entre trabalhadores de saúde [Instruments and impacting factors on standard precautions knowledge among health workers]. Enfermería Global. 2016;15(1):272-88. https://doi.org/10.6018/ eglobal.15.1.223561.

14. von Elm E, Altman DG, Egger M, et al. The Strengthening the Reporting of Observational Studies in Epidemiology (STROBE) statement: guidelines for reporting observational studies. Ann Intern Med. 2007;147(8):573-7. PMID: 17938396; https://doi.org/10.7326/00034819-147-8-200710160-00010. Erratum in: Ann Intern Med. 2008;148(2):168.

15. Valim MD, Pinto PA, Marziale MHP. Questionário de conhecimento sobre as precauções-padrão: estudo de validação para utilização por enfermeiros brasileiros [Questionnaire on standard precaution knowledge: validation study for Brazilian nurses use]. Texto Contexto Enferm. 2017;26(3):e1190016. https://doi.org/10.1590/010407072017001190016.

16. Valim MD, Marziale MH, Hayashida M, Rocha FL, Santos JL. Validity and reliability of the Questionnaire for Compliance with Standard Precaution. Rev Saude Publica. 2015;49:87. PMID: 26759967; https:// doi.org/10.1590/S0034-8910.2015049005975.

17. Brasil. Ministério da Saúde. Portaria no 389, de 13 de março de 2014. Define os critérios para a organização da linha de cuidado da Pessoa com Doença Renal Crônica (DRC) e institui incentivo financeiro de custeio destinado ao cuidado ambulatorial prédialítico. Diário Oficial da União da República Federativa do Brasil. 2014;151(50). Available from: https://bvsms.saude.gov.br/bvs/ saudelegis/gm/2014/prt0389_13_03_2014.html. Accessed in 2021 (Aug 10).

18. Machado MH, Aguiar Filho W, de Lacerda WF, et al. Características gerais da enfermagem: o perfil sócio demográfico. Enferm Foco. 2016;7(ESP):914. Available from: http://revista.cofen.gov.br/index.php/enfermagem/ article/view/686/296. Accessed in 2021 (Aug 10).

19. Brevidelli MM, Cianciarullo TI. Psychosocial and organizational factors relating to adherence to standard precautions. Rev Saude Publica. 2009;43(6):907-16. PMID: 19967259; https://doi.org/10.1590/s003489102009010700001.

20. Souza TPM, de Souza Rocha IL, da Cruz YA, et al. Fatores impactantes na adesão e conhecimento da equipe de enfermagem às precauçõespadrão. Enfermería Global. 2020;19(1):413-59. http://dx.doi.org/10.6018/ eglobal.19.1.373851.

21. da Cruz FF, Gonçalves RP, Raimundo SR, Amaral MS. Segurança do paciente na UTI: uma revisão da literatura [Patient safety in the ICU: a review of the literature]. Revista Científica FacMais. 2018;XII(1):167-87. Available from: https://revistacientifica.facmais. com.br/wp-content/uploads/2018/06/12.-SEGURAN\%C3\%87ADO-PACIENTE-NA-UTI-UMA-REVIS\%C3\%83O-DA-LITERATURA.pdf. Accessed in 2021 (Aug 10).
22. Silva DMD, Marques BM, Galhardi NM, Orlandi FS, Figueiredo RM. Hands hygiene and the use of gloves by nursing team in hemodialysis service. Rev Bras Enferm. 2018;71(4):1963-9. PMID: 30156684; https:// doi.org/10.1590/0034-7167-2017-0476.

23. Trannin KPP, Campanharo CRV, Lopes MCBT, Okuno MFP, Batista REA. Adesão à higiene das mãos: intervenção e avaliação. Cogitare Enferm. 2016;21(2):1-7. https://doi.org/10.5380/ce.v21i2.44246.

24. Oliveira AC, Paula AO. Intervenções para elevar a adesão dos profissionais de saúde à higiene de mãos: revisão integrativa. Rev. Eletr. Enferm. 2013;15(4):1052-60. https://doi.org/10.5216/ree.v15i4.21323.

25. Martins Mendonça K, Ferreira Veiga Tipple A, Custódia Silva e Sousa A, Severino Pereira M, Rapparini C. Accidentes con material biológico en los servicios de urgencia y emergencia. Cienc Enferm. 2014;20(2):65-71. http://dx.doi.org/10.4067/S0717-95532014000200007.

26. Carvalho DC, Rocha JC, Gimenes MCA, Santos EC, Valim MD. Acidentes de trabalho com material biológico na equipe de enfermagem de um hospital do Centro-Oeste brasileiro. Esc Anna Nery. 2018;22(1):e20170140. https://doi.org/10.1590/2177-9465-EAN-2017-0140.

27. Ribeiro AS, Gabatz RIB, Neves ET, de Mello Padoin SM. Caracterização de acidente com material perfurocortante e a percepção da equipe de enfermagem. Cogitare Enferm. 2009;14(4):660-6. http://dx.doi. org/10.5380/ce.v14i4.16379.

Authors' contributions: Medeiros LP: conceptualization (equal), data curation (lead), formal analysis (lead), investigation (equal), methodology (equal), project administration (equal), validation (equal), visualization (equal), writing-original draft (equal) and writingreview and editing (equal); Miranda KS: data curation (equal), formal analysis (equal), funding acquisition (equal), investigation (equal), methodology (equal), project administration (equal), supervision (equal), validation (equal), visualization (equal), writing-original draft (equal) and writing-review and editing (equal); Gonçalves TM: conceptualization (equal), data curation (equal), formal analysis (equal), funding acquisition (equal), investigation (equal), methodology (equal), project administration (equal), validation (equal), visualization (equal), writing-original draft (equal) and writing-review and editing (equal); Rodrigues DDM: conceptualization (equal), data curation (equal), formal analysis (equal), funding acquisition (equal), investigation (equal), methodology (equal), project administration (equal), supervision (equal), validation (equal), visualization (equal), writing-original draft (equal) and writing-review and editing (equal); Hiraki KRN; conceptualization (equal), data curation (equal), formal analysis (equal), funding acquisition (equal), investigation (equal), methodology (equal), project administration (equal), supervision (equal), validation (equal), visualization (equal), writing-original draft (equal) and writing-review and editing (equal); Valim MD: conceptualization (equal), data curation (equal), formal analysis (equal), funding acquisition (equal), investigation (equal), methodology (equal), project administration (equal), supervision (equal), validation (equal), 
visualization (equal), writing-original draft (equal) and writing-review and editing (equal); Taminato M: conceptualization (equal), data curation (equal), formal analysis (equal), funding acquisition (equal), investigation (equal), methodology (equal), project administration (equal), supervision (equal), validation (equal), visualization (equal), writing-original draft (equal) and writing-review and editing (equal); and Morais RB: conceptualization (lead), data curation (lead), formal analysis (lead), funding acquisition (lead), investigation (lead), methodology (lead), project administration (lead), supervision (lead), validation (lead), visualization (lead), writing-original draft (lead) and writing-review and editing (lead). All authors reviewed and approved the final version for publication

Acknowledgements: We are grateful to Cintia Yurie Yamachi for her contribution to the statistical analysis of the data

Sources of funding: There are no funders to report for this submission Conflict of interest: The authors declare that they did not have any conflicts of interest

Date of first submission: April 8, 2021

Last received: April 8, 2021

Accepted: July 23, 2021

\section{Address for correspondence:}

Richarlisson Borges de Morais

Av. Prof. José Inácio de Souza, s/no - Bloco 4K — 5o Piso

Umuarama — Uberlândia (MG) — Brasil

CEP 38400-732

Tel. (+55 34) 3225-8456

E-mail: richarlissonmorais@ufu.br 